\title{
Are the Current Smart Grid Concepts Likely to Offer a Complete Smart Grid Solution?
}

\author{
Albana Ilo \\ Institute for Energy Systems and Electrical Drives, TU Wien, Vienna, Austria \\ Email: albana.ilo@tuwien.ac.at
}

How to cite this paper: Ilo, A. (2017) Are the Current Smart Grid Concepts Likely to Offer a Complete Smart Grid Solution? Smart Grid and Renewable Energy, 8, 252-263. https://doi.org/10.4236/sgre.2017.87017

Received: June 6, 2017

Accepted: July 16, 2017

Published: July 19, 2017

Copyright $\odot 2017$ by author and Scientific Research Publishing Inc. This work is licensed under the Creative Commons Attribution International License (CC BY 4.0).

http://creativecommons.org/licenses/by/4.0/

\section{(c) (i) Open Access}

\begin{abstract}
At present, the structure of power systems is greatly changing due to the penetration of decentralized generations. Although they encompass a high flexibility potential, their large-scale penetration interferes with the power system operation at all voltage levels. To get rid of this flaw and exploit their flexibility, different concepts like Virtual Power Plants, Microgrids and Cellular Approach have been introduced but still no solution is in sight. Under these conditions, it seems quite intriguing to find out whether these concepts are likely to offer a complete solution or not. This paper presents ten criteria to assess the complete Smart Grid solution and introduces a comprehensive evaluation system based on cloud-charts. The paper looks into the already existing solutions, which are respectively based on Virtual Power Plants, Microgrids and Cellular Approach concepts. The investigations have shown that none of these solutions meets all criteria necessary for a complete Smart Grid solution. Even a combination of different criteria fails to yield the desired results.
\end{abstract}

\section{Keywords}

Assessment System, Cellular Approach, Evaluation Criteria, Microgrids, Smart Grid, Virtual Power Plants

\section{Introduction}

The power industry has been more than ever challenged in the past 20 years. Its liberalization [1] and the establishment of the electricity market [2] gave the power industry the first blow, followed by other difficulties caused by the introduction of new renewable energy resources and the decentralized generation, DG. At present, many countries are moving towards a renewable energy portfolio [3] [4] [5] [6], which increases the fluctuations in power systems. The structure of electricity supply is also changing drastically due to many decentralized generation units [7] [8] [9] [10], each having a possibility to interfere with the 
system operation at all voltage levels. This kind of development of the energy industry is causing serious problems in the management and use of the existing transmission [11] [12] [13] [14] and distribution [15] [16] [17] grids.

In order to solve those problems, various concepts such as Virtual Power Plants, VPP, [18]-[23], Microgrids [24]-[29] have been developed for years. Many scientists in different countries have started to use these concepts since first introduced in 2003, each of them providing different solutions related to their individual cases. Most of them succeeded in changing the fundamental definition of these concepts to meet the specific requirements set in their own projects. The detailed definitions of Virtual Power Plants [20] and Microgrids [24] concepts are still being discussed in various technical-scientific forums worldwide.

In 2008, a new concept called the Cellular Approach was introduced into the Smart Grid research area [30] [31] [32]. A simple comparison shows that, similar to Microgrids [29], the Cellular Approach [31] uses the same Matryoshka-doll principle in setting of cells. As in [33], both concepts are intertwined with each other and the mixed name of "Smart Micro Grid Cell" was since introduced.

The introduction and use of Smart Grid concepts have caused many other problems [21] [29] [34] [35] in an effort to solve the challenge of DG integration. The proposed solutions were mostly of a partial character, in many cases very complicated and with extremely ramified control schemes, which makes their practical implementation in a large scale almost impossible. Therefore, none of the solutions has practically crossed the boundaries of a research project. These problems, accumulated over time, sooner or later endanger the reliable and safe operation of power systems.

Amidst such a research landscape with so many different concepts, it appears intriguing to pursue the question whether the already existing concepts or their combination are likely to support a complete solution for Smart Grids. It is to be expected that any future extension of them or the development of the new concepts should enable the development of a complete Smart Grid solution.

The main thrust of this paper is to identify the evaluation criteria for a complete Smart Grid solution. This study first focuses on the definition of the complete solution, followed by the identification of ten assessment criteria and establishment of a comprehensive evaluation system for a complete Smart Grid solution. Finally, the study verifies to what extent the popular concepts of Virtual Power Plant, Microgrids, and Cellular Approach meet the defined criteria.

\section{Complete Solution}

There are several definitions of the term Smart Grid [36] [37] [38] [39]. For this study I have used the definition given in [36] which refers to the term "Smart Grid" as a modernization of the electricity delivery system to the extent that it monitors, protects and automatically optimizes the operation of its interconnected elements-from the central and distributed generator through the highvoltage transmission network and the distribution system to industrial users and 
building automation systems, to energy storage installations and to end-use consumers and their thermostats, electric vehicles, appliances and other household devices.

Based on the above Smart Grid definition, the study defines the complete Smart Grid solution as an answer seeking to solve the Smart Grid problems as a whole. A Smart Grid complete solution should guarantee a stable, reliable and cost-effective operation of a more environmentally-friendly smart power system. It should also have the ability to ride through the transition phase and further on without causing any problems.

\section{Evaluation System}

A comprehensive evaluation system make it possible to assess the similarities, differences, strengths and weaknesses of competing complete Smart Grid solutions. A well-integrated evaluation system ensures soundness and reasonableness of the development process for a complete Smart Grid solution.

The evaluation system consists of the assessment criteria and evaluation cloud-chart.

\subsection{Assessment Criteria}

The established assessment criteria consist of a set of benchmarks or yardsticks against which the accomplishment, conformance, performance, and suitability of a complete Smart Grid solution are measured. They are established by considering the following properties: each of them should be unambiguous, comprehensive, direct, operational and understandable [50].

The evaluation criteria of a complete Smart Grid solution have to consider the following:

\section{1) All voltage levels of power grids}

Based on [36], both the transmission (very high and high voltage level) and distribution (medium and low voltage level) grid are included to the Smart Grid definition. And rightly so, although different parts of the grid are operated from different utilities, the power grid is one unique giant physical system with very complicated interdependencies [28] [36] between different parts of it. The isolated consideration of different grid parts may challenge the reliable operation of the neighboring ones. As reported in [11], the local control of the decentralized generation connected in a medium voltage grid has created a remarkable uncontrolled reactive power flow in the high voltage grid. Therefore, it is indispensable to consider all voltage levels of power grids for a suitable and complete Smart Grid solution.

\section{2) All electricity producers regardless of size and technology}

Based on [36], all electricity producers from the central up to the distributed generators are included into the Smart Grid definition. Apart from the big power plants, the distributed generators are gaining in popularity. They are small sized, based on different technologies and can be connected across all distribution grids. Similar to the large power plants, they show a considerable flexibility, 
but they can adversely affect the network operation, when they operate in an uncoordinated way. Therefore, taking into consideration all electricity producers regardless of their size and technology is a cornerstone for a successful and complete Smart Grid solution.

\section{3) All electricity storages regardless of size and technology}

Historically, large pumped hydro power plants have been widely used for electricity storage. Nowadays, driven from the advanced technologies, smaller storage units are used. These units are connected across all distribution grids up to the customer plants and can contribute to their reliable operation. Thus considering all storage devices, regardless of their size and technology, opens up extraordinary perspectives for an economical operation of the grid and an effective use of the installed capacities of power supplies.

\section{4) Consumers and prosumers}

Nowadays, many consumers have changed their behavior, mainly because they have installed PVs on their roofs. These consumers, now transformed into prosumers, are able to consume and inject power into the power grid and deliver flexibility for its operation.

\section{5) All power system operation processes}

It is important to guarantee a secure, reliable and economic operation of the smart power system in the future as well. That means that all the processes needed to operate a power system-i.e. power system monitoring, limit assessment, static and dynamic security, congestion management, outage management, load shedding management, generation load balance, reserve management, restauration, demand response, etc. [40]—must be supported by the complete Smart Grid solution.

\section{6) Data privacy protection}

Data privacy gets a great relevance only when the prosumers actively participate in the grid operation. The prosumer participation in the grid operation leads to an increase in the use of the information dealing with their private consumption and daily private activities.

\section{7) Avoidance of big data transfer}

Electricity is generally taken for granted and should be available on demand. In many cases, the deployment of the existing Smart Grid solutions leads to a big data transfer. The latter requires the integration of new ICT technologies, which are largely exposed to cyber-attacks and thus reduce the reliability of supply. The minimization of data transfer and the use of secure communication media are crucial for a reliable and secure power supply.

\section{8) Market aspect}

Electricity market is already an integral part of the power industry. Its flourishing is one of the essential aspects of smart power grids. There are even Smart Grid definitions underlining that Smart Grids are mainly oriented to the electricity market [38].

\section{9) Standardized structure}

Standardized structures can be easily deployed into the power industry and 
contribute to an economical, qualitative, simple and straightforward development and implementation of a given solution. They are fundamental to the large-scale implementation of the complete Smart Grid solution.

\section{0) Transition process}

Electricity is one of the fundamentals of today's life because we depend on electricity for such rudimentary needs as water, food, health care, communications, etc. The electricity industry is classified as one of the critical infrastructures [41] of our society. This means that smart power systems should operate reliably during their transition time as well as afterwards. Therefore, the availability of a smooth transition process from the actual power systems and applications up to the smart power systems and the corresponding applications is an indispensable criterion for the complete Smart Grid solution.

\subsection{Evaluation Cloud-Chart}

Evaluation cloud-charts are used to present the assessment results in order to facilitate their interpretation and comparison of different cases. Figure 1 shows the evaluation cloud-chart of an ideal, complete Smart Grid solution, when all criteria are fulfilled as a whole. The study performs only a qualitative analysis and draws results, which should be treated as a trend rather than a sharp rating.

\section{Discussion}

This chapter deals with the first attempt made to evaluate different solutions, which are based on the most popular Smart Grid concepts like VVP, Microgrids and Cellular Approach. The evaluation is based on the evaluation criteria defined above. I have done an extensive research while preparing for this study. However, given the large volume of publications in this area, I might have missed some relevant information that I am not aware of. Nevertheless, this study seeks to be the first ever evaluation attempt aiming at further developing Smart Grid concepts.

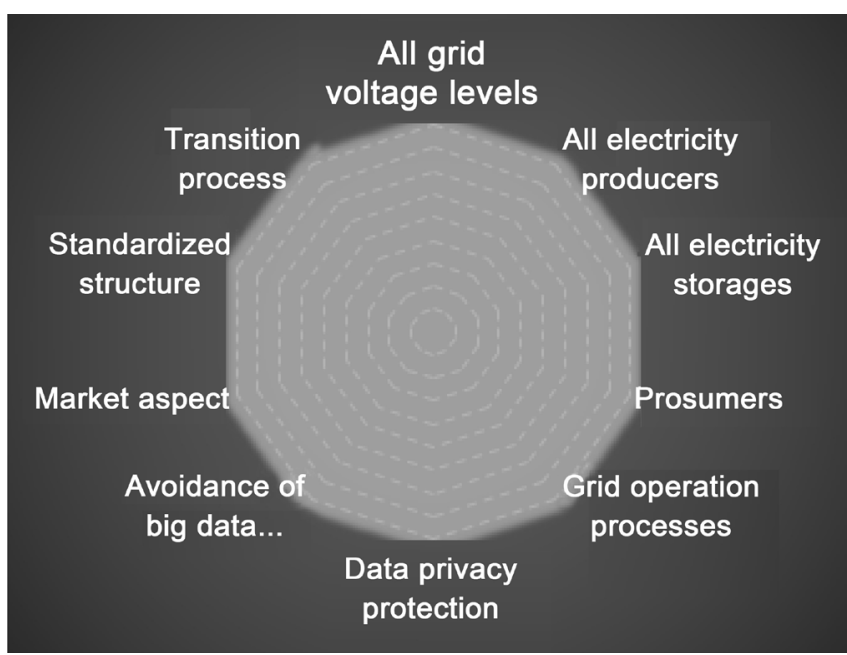

Figure 1. The evaluation cloud-chart of an ideal smart grid solution. All criteria are fulfilled as a whole. 


\subsection{Virtual Power Plant}

Figure 2(a) shows the cloud-chart for the Smart Grid solution, which is based on the VPP concept. The VPP is composed of a number of Distributed Energy Resources (DER) of various technologies with various operating patterns and availability, the characteristics of the VPP may vary significantly in time. This concept was originally designed to enable the small decentralized electricity producer to participate into the market. Later, it was found out that the complex management processes of the grid could not be considered with this concept [18]. Therefore, the VPP concept was split up into two, the Commercial VPP (CVPP) and the Technical VPP (TVPP) [42]. The CVPP is a representation of a portfolio of DER that can be used to participate in energy markets in the same manner as transmission-connected generating plant, while the TVPP provides visibility of DER to the system operator(s); it allows DER to contribute to system management activities and facilitates use of DER capacity, providing system balancing at the lowest cost. The power grid does not appear to be treated explicitly. Therefore the first criterion that requires that all voltage levels of power grids are taken into consideration seems not to be met. All studies based on the VPP consider the distributed generation and storage [18]-[23]. The big power and storage plants, which are connected to the high voltage grid, are not taken into account. Therefore, criteria 2 and 3, which take into consideration all producers and storages regardless of size and technology are not fulfilled as a whole. Consumers and prosumers are fully taken into account, thus criterion 4, requiring that consumers and prosumers are taken into consideration, is met in its entirety. Criterion 5 deals with the consideration of all power system operation processes. The generation-balance process is being broadly treated. Other grid-related operating processes [40] are not treated or are still part of the research process in the context of the TVPP. Therefore, criterion 5 can hardly be fulfilled in this case. Solutions based on the VPP require a big data exchange between the DERs and the aggregators, as well as TSOs and DSOs [42], thus creating not only an ICT challenge but also a data privacy issue [11] [13]. A lot of research work has been carried out in this area, thus criterion 6 on data privacy protection results to be partially fulfilled. Criterion 7 , which requires the avoidance of the big data transfer [42], is not fulfilled. Criterion 8, which deals with the market aspect, is met in its entirety. All solutions derived from the VPP are very complex with extremely ramified schemes [11] [13] [43] [44] [45] [46] [47]. No standardized structure could be identified and, as a result, criterion 9 on the standardized structure is not met. Criterion 10 on the transition process is not dealt with in literature, so it is not fulfilled.

\subsection{Microgrids}

Figure 2(b) shows the cloud-chart of the Smart Grid solution, which is based on the Microgrid concept. Although a detailed definition of Microgrids is still under discussion in technical forums, a Microgrid can be described as a cluster of loads, distributed generation units and Energy Storage Systems operated in 


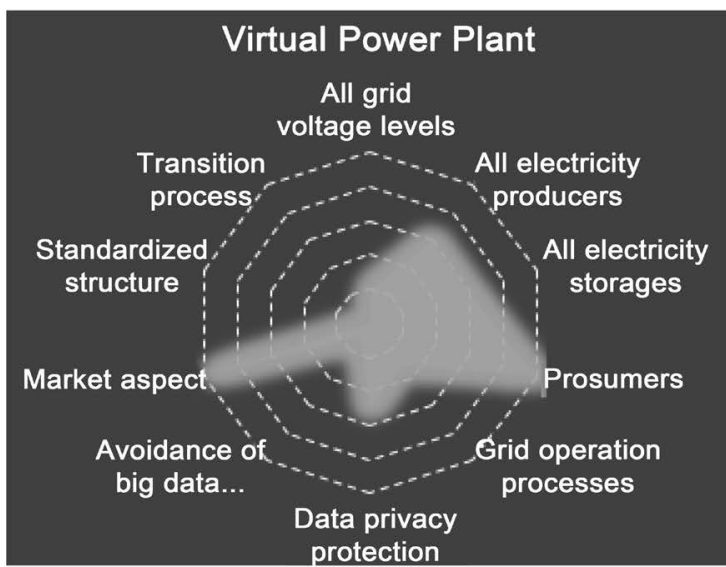

(a)

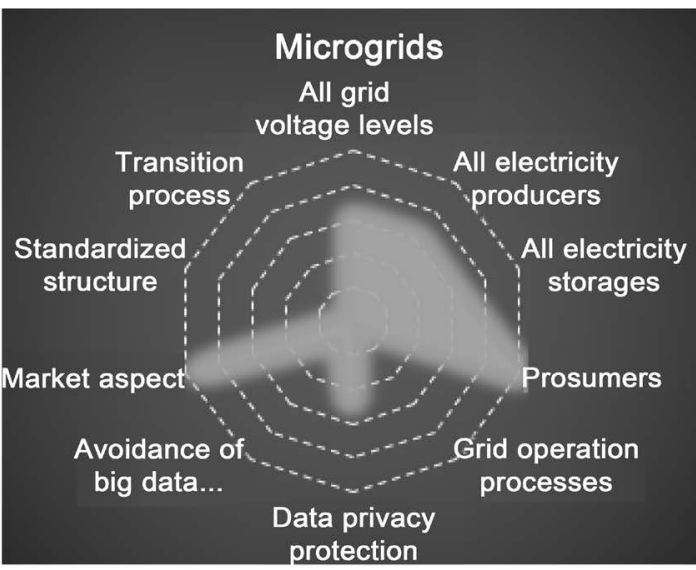

(b)

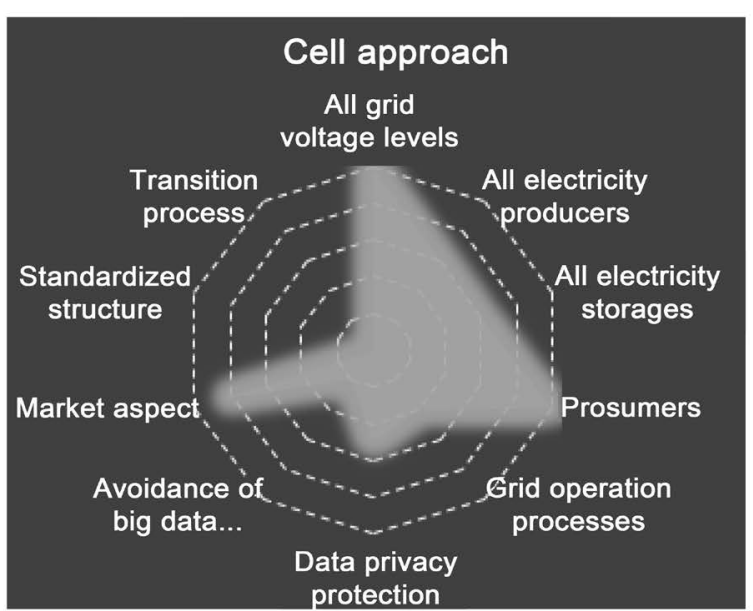

(c)

Figure 2. The evaluation cloud-chart of smart grid solutions, which are based on different concepts: (a) Virtual Power Plants; (b) Microgrids; (c) Cellular Approach.

coordination to reliably supply electricity, connected to the host power system at the distribution level at a single point of connection, the point of common coupling [24]. As a result of the definition, the power grid does not seem to be treated in its entirety. Microgrid applies only to distribution, which means in the medium and low voltage grid. High voltage grid is included in the "host power system" [24], "Macrogrid" [48], which per definition is not part of Microgrid. Therefore the first criterion that requires that all voltage levels of power grids are taken into consideration seems not to be met in its entirety. Distributed generation and storage are a fundamental part of Microgrids, but large power plants and storages that are connected to the high voltage grid are not taken into account. Consequently, criteria 2 and 3, which take into consideration all producers and storages regardless of size and technology are not fulfilled as a whole. Consumers and prosumers are fully taken into account, thus criterion 4 , requiring that consumers and prosumers are taken into consideration, is met in its entirety. Criterion 5 deals with the consideration of all power system operation processes. Although a Microgrid should be capable of operating in grid-connected and stand-alone modes [24], no any contribution can be found that de- 
scribes the grid-connected regime. As a result also the power system operation processes are not treated. In these conditions criterion 5 a hardly be fulfilled. Data privacy is a very important issue in the Microgrids solutions when there are needed cooperation's among subsystems [35]. A lot of research work has been carried out in this area [48], thus criterion 6 on data privacy protection results to be partially fulfilled. Microgrids solutions requires big data transfer thus creating an ICT challenge [48]. Additionally, the usage of the Game Theory for the Smart Grid solution increases drastically the risk of cyber-attacks. Also here a lot of research has been carried out, hence criterion 7 , which requires the avoidance of big data transfer results somewhat fulfilled. Criterion 8 deals with the consideration of the market aspect. There are many attempts to implement a market environment using a Multi-agent System [25], or market model based on Game Theory [49]. Therefore, criterion 8 can be considered fulfilled. No standardized structure could be identified and, as a result, criterion 9 on the standardized structure is not met. Criterion 10 on the transition process is not dealt with in the literature, so it is not fulfilled.

\subsection{Cellular Approach}

Figure 2(c) shows the cloud-chart for the Smart Grid solution, which is based on the Cellular Approach. It can be seen as a self-controlled small Microgrid, which is integrated with a modular Smart Grid ICT infrastructure [3]. The distribution grid is considered through "connection corridors" while the transmission grid through "transmission corridors" [31]. Therefore the first criterion that requires that all voltage levels of power grid are taken into consideration seems to be fulfilled in its entirety. The Cellular Approach applies on the distributed producers and storages [31], but the big power plants and storages which are connected to the high voltage grid are not considered. Therefore, criteria 2 and 3 , which take into consideration all producers and storages regardless of size and technology are not fulfilled as a whole. Consumers and prosumers are fully taken into account, thus criterion 4, requiring that consumers and prosumers are taken into consideration, is met in its entirety. Criterion 5 deals with the consideration of all power system operation processes [40]. Cellular Approach deals mainly with the process of load-generation balance combined with those of Demand Side Management. Other essential operations [40] are in fact not addressed. Therefore, criterion 5 seems to be fulfilled to some extent. Data privacy, criterion 6 , and the avoidance of big data transfer, criterion 7 , are the biggest challenges in the realization of the Cellular Approach. Indeed, researchers have come to the conclusion that further research projects and concepts are needed to develop robust solutions against cyber-attacks [32]. Therefore, criteria 6 and 7 seem to be little fulfilled. The Cellular Approach supports and requires a new market design and business models which are already in process [31]. Therefore criterion 8, which deals with market aspect, is not fulfilled as a whole. No standardized structure could be identified and, as a result, criterion 9 on the standardized structure is not met. Criterion 10 on the transition process is not dealt 
with in the literature, so it is not fulfilled.

The evaluation cloud-chart of Smart Grid solutions presented in Figure 2 shows that none of the solutions fulfill all the evaluation criteria as a whole. They all show almost the same shape, with an important difference that the grid consideration is successively increased from the VPP solution, Microgrid and then up to the Cellular Approach one. The evaluation cloud-charts are not complementary to each other, which means that the combination of solutions based on various existing Smart Grid concepts, VPP, Microgrids and Cellular Approach, cannot provide a complete Smart Grid solution.

\section{Conclusion}

Smart Grids are widely elaborated in the last 15 years, but still no complete solution has been found. This study provides the first ever definition of a complete Smart Grid solution and introduces a comprehensive evaluation system consisting of ten clear and unambiguous assessment criteria. None of the solutions based on various existing Smart Grid concepts, VPP, Microgrids and Cellular Approach, or their combination fulfills all the evaluation criteria as a whole. However, this study concludes that other concepts and paradigms are needed to provide the complete Smart Grid solution.

\section{References}

[1] Bacon, R.W. (1995) Privatization and Reform in the Global Electricity Supply Industry. Energy and the Environment, 20, 119-143.

[2] Cardella, J.B., Hittb, C.C. and Hogan, W.W. (1997) Market Power and Strategic Interaction in Electricity Networks. Resource and Energy Economics, 19, 109-137. https://doi.org/10.1016/S0928-7655(97)00006-7

[3] European Commission (2016) Directive of the European Parliament and of the Council on the Promotion of the Use of Energy from Renewable Sources. https://ec.europa.eu/energy/sites/ener/files/documents/1_en_act_part1_v7_1.pdf

[4] Fleischmann, D. (2016) Renewable Energy Was 16.9 Percent of US Electric Generation in the First Half of 2016.

http://www.renewableenergyworld.com/articles/2016/08/renewable-energy-was-169-percent-of-u-s-electric-generation-in-the-first-half-of-2016.html

[5] Clean Energy Council (2015) Clean Energy Australia Report. https://www.cleanenergycouncil.org.au/policy-advocacy/reports/clean-energy-austr alia-report.html

[6] Chu, J. (2015) China's Fast Track to a Renewable Future. https://www.theclimategroup.org/sites/default/files/archive/files/RE100-China-anal ysis.pdf

[7] Barker, P.P. and de Mello, R.W. (2000) Determining the Impact of Distributed Generation on Power Systems: Part1-Radial Distribution Systems. Power Engineering Society Summer Meeting, Seattle, 16-20 July 2000, 1645-1656.

https://doi.org/10.1109/pess.2000.868775

[8] Ackermann, T., Anderson, G., Söder, L. (2001) Distributed Generation: A Definition. Electric Power System Research, 57, 195-204. https://doi.org/10.1016/S0378-7796(01)00101-8

[9] El-Khattam, W. and Salama, M.M.A. (2004) Distributed Generation Technologies, 
Definitions and Benefits. Electric Power Systems Research, 71, 119-128. https://doi.org/10.1016/j.epsr.2004.01.006

[10] Owens, B. (2014) The Rise of Distributed Power. https://www.ge.com/sites/default/files/2014\%2002\%20Rise\%20of\%20Distributed\%2 0Power.pdf

[11] Lund, P. (2007) The Danish Cell Project-Part 1: Background and General Approach. Proceedings of the IEEE Power Engineering Society General Meeting, 1 June 2007, Tampa, 24-28.

[12] Schäfer, P., Vennegeerts, H., Krahl, S. and Moser, S.A. (2015) Derivation of Recommendations for the Future Reactive Power Exchange at the Interface between Distribution and Transmission Grid. Proceedings of the $23 \mathrm{rd}$ Conference and Exhibition on Electricity Distribution, CIRED, Lyon, 15-18 June 2015, 1-5.

[13] Martensen, N., Kley, H., Cherian, S., Pacific, O. and Lund, P. (2009) The Cell Controller Pilot Project: Testing a Smart Distribution Grid in Denmark. http://www.gridwiseac.org/pdfs/forum_papers09/kley.pdf

[14] Ilo,A., Gawlik, W., Schaffer, W. and Eichler, R. (2015) Uncontrolled Reactive Power Flow Due to Local Control of Distributed Generators. Proceedings of the $23 \mathrm{rd}$ Conference and Exhibition on Electricity Distribution, CIRED, Lyon, 15-18 June 2015, 1-5.

[15] Prata, R.A. (2006) Impact of Distributed Generation Connection with Distribution Grids-Two Case-Studies. IEEE in Power Engineering Society General Meeting, 19, 1-22. https://doi.org/10.1109/pes.2006.1709465

[16] Hidayatullah, N.A., Paracha, Z.J. and Kalam, A. (2009) Impacts of Distributed Generation on Smart Grid. Proceedings of the International Conference of Electrical Energy and Industrial Electronic System, Penang, 7-8 December 2009, 218-221.

[17] Kerber, G., Witzmann, R. and Sappl, H. (2009) Voltage Limitation by Autonomous Reactive Power Control of Grid Connected Photovoltaic Inverters. Proceedings of Conference on Compatibility and Power Electronics, Badajoz, 20-22 May, 129-133.

[18] Dielmann, K. and Veiden, A. (2003) Virtual Power Plants (VPP) A New Perspective for Energy Generation? Modern Technique and Technologies, Tomsk, 7-13 April 2003, 18-20.

[19] Bignucolo, F., Caldon, R., Prandoni, V., Spelta, S. and Vezzola, M. (2006) The Voltage Control on MV Distribution Networks with Aggregated DG Units (VPP). Proceedings of the 41 st International Universities Power Engineering Conference, Newcastle, 6-8 September 2006, 187-192. https://doi.org/10.1109/UPEC.2006.367741

[20] Othman, M.M., Hegazy, Y.G. and Abdelaziz, A.Y. (2015) A Review of Virtual Power Plant Definitions, Components, Framework and Optimization. International Electrical Engineering Journal, 6, 2010-2024.

[21] Plancke, G., Vos, K.D., Belmans, R. and Delnooz, A. (2015) Virtual Power Plants: Definition Applications and Barriers to the Implementation in the Distribution System. Proceedings of 12 th International Conference on the European Energy Market, Lisbon, 20-22 May 2015, 1-5. https://doi.org/10.1109/eem.2015.7216693

[22] El-Bakari, K. and Kling, W.L. (2010) Virtual Power Plants: An Answer to Increasing Distributed Generation. Proceedings of Innovative Smart Grids Technologies Conference Europe, Gothenburg, 10-13 October 2010, 1-7.

[23] Kieny, C., Berseneff, B., Hadjsaid, N., Besanger, Y. and Maire, J. (2009) On the Concept and the Interest of Virtual Power Plant: Some Results from the European Project FENIX. Proceedings of Power \& Energy Society General Meeting, Calgary, 2630 July 2009, 1-6. https://doi.org/10.1109/pes.2009.5275526 
[24] Olivares, D.E., et al. (2014) Trends in Microgrid Control. IEEE Transactions on Smart Grids, 5, 1905-1919. https://doi.org/10.1109/TSG.2013.2295514

[25] Dimeas, A.L. and Hatziargyriou, N.D. (2005) Operation of a Multiagent System for Microgrid Control. IEEE Transaction on Power Systems, 20, 1447-1455. https://doi.org/10.1109/TPWRS.2005.852060

[26] Zhu, T., et al. (2013) Sharing Renewable Energy in Smart Microgrids. Proceedings of International Conference on Cyber-Physical Systems, Philadelphia, 8-11 April 2013, 219-228. https://doi.org/10.1145/2502524.2502554

[27] Doolla, S. and Priolkar, J. (2011) Analysis of Frequency Control in Isolated Microgrids. Proceedings of IEEE PES Innovative Smart Grid Technologies, Kollam, 1-3 December 2011, 1-6.

[28] Lasseter, R.H., et al. (2002) The CERTS Microgrid Concept. White Paper for Transmission Reliability Program. Office of Power Technologies, U.S. Department of Energy, Washington DC, 1-27.

[29] Soshinskaya, M., et al. (2014) Microgrids: Experiences, Barriers and Success Factors. Renewable and Sustainable Energy Reviews, 40, 659-672.

https://doi.org/10.1016/j.rser.2014.07.198

[30] Buchholz, B., Nestle, D. and Kiessling, A. (2009) Individual Customers' Influence on the Operation of Virtual Power Plant. Proceedings of IEEE Power and Energy Society General Meeting, Calgary, 26-30 July 2009, 1-6. https://doi.org/10.1109/pes.2009.5275401

[31] Benz, T., et al. (2015) The Cellular Approach. https://shop.vde.com/de/copy-of-vde-studie-der-zellulare-ansatz

[32] KieBling, A. (2013) Beiträge von moma zur Transformation des Energiesystems für Nachhaltigkeit, Beteiligung, Regionalität und Verbundheit. Modellstadt Mannheim (moma), Projekt Abschlussbericht.

https://www.ifeu.de/energie/pdf/moma_Abschlussbericht_ak_V10_1_public.pdf

[33] Kleineidam, G., Krasser, M. and Reischböck, M. (2016) The Cellularapproach: Smart Energyregion Wunsiedel. Test Bed for Smart Grid, Smart Metering and Smart Home Solutions. Electrical Engineering, 4, 1-6.

https://www.springerprofessional.de/the-cellular-approach-smart-energy-region-w unsiedel-testbed-for-/10701984

[34] Schiller, C. and Fassmann, S. (2010) The Smart Micro Grid: It Challenges for Energy Distribution Grid Operators. International Business Machine, New York, 36-42. https://www.smartgrid.gov/files/The_Smart_Micro_Grid_IT_Challenges_for_Energ y_Distribution_G_201002.pdf

[35] McDaniel, P. and McLaughlin, S. (2009) Security and Privacy Challenges in the Smart Grid. IEEE Security Privacy, 7, 75-77. https://doi.org/10.1109/MSP.2009.76

[36] Myrda, P. (2009) Smart Grid Enabled Asset Management. Electric Power Research Institute, Paolo Alto.

[37] European Commission, Directorate-General for Energy (2011) Smart Grid Mandate. Standardization Mandate to European Standardization Organizations to Support European Smart Grid Deployment. European Commission, Brussels.

[38] German Association of Energy and Water Industries (2013) BDEW RoadmapRealistic-Steps for the Implementation of Smart Grids in Germany, German Association of Energy and Water Industries, Berlin. https://www.bdew.de/internet.nsf/id/816417E68269AECEC1257A1E0045E51C/\$file /Endversion_BDEW-Roadmap_englisch.pdf

[39] Bollen, M. (2011) The Smart Grid-Adapting the Power System to the New Chal- 
lenges. Morgan and Claypool Publishers, San Francisco.

[40] Vaahedi, E. (2014) Practical Power System Operation, John Wiley \& Sons, New York. https://doi.org/10.1002/9781118915110

[41] John, M. and Parfomak, P. (2004) Critical Infrastructure and Key Assets: Definition and Identification. Resources, Science \& Industry Division, Library of Congress, Washington DC. https://fas.org/sgp/crs/RL32631.pdf

[42] Pudjianto, D., Ramsay, C. and Strbac, G. (2007) Virtual Power Plant and System Integration of Distributed Energy Resources. IET Renewable Power Generation, 1, 10-16. https://doi.org/10.1049/iet-rpg:20060023

[43] Taft, J. and Martini, P.D. (2012) Ultra Large-Scale Power System Control Architecture, a Strategic Framework for Integrating Advanced Grid Functionality. http://www.cisco.com/web/strategy/docs/energy/control_architecture.pdf

[44] Moslehi, K. and Kumar, R.A. (2010) Reliability Perspective of the Smart Grid. IEEE Transactions on Smart Grid, 1, 57-64. https://doi.org/10.1109/TSG.2010.2046346

[45] Grijalva, S. and Tariq, M.U. (2011) Prosumer-Based Smart Grid Architecture Enables a Flat, Sustainable Electricity Industry. Proceedings of Innovative Smart Grid Technologies Conference, Anaheim, 17-19 January 2011, 1-6. http://ieeexplore.ieee.org/stamp/stamp.jsp?arnumber $=5759167$

[46] Bose, A. (2010) Smart Transmission Grid Applications and Their Supporting Infrastructure. IEEE transactions on Smart Grid, 1, 11-19. https://doi.org/10.1109/TSG.2010.2044899

[47] Gallagher, J.T. (2014) Moving towards Utility 2.0-New York State and the U.S.. Proceedings of Eurelectric Smart Grid Projects Academy, 6th Workshop: Smart Distribution Management, Brussels, 24 September 2014, 17-26. http://www.eurelectric.org/media/153323/workshop6_presentations.pdf

[48] Saad, W., et al. (2012) Game Theoretic Methods for the Smart Grid-An Overview of Microgrids Systems, Demand-Side Management, and Smart Grid Communications. IEEE Signal Processing Magazine, 29, 86-105.

http://ieeexplore.ieee.org/stamp/stamp.jsp?arnumber=6279592 https://doi.org/10.1109/MSP.2012.2186410

[49] Wang, Z., Yang, K. and Wang, X. (2013) Privacy-Preserving Energy Scheduling in Microgrid Systems. IEEE transactions on Smart Grid, 4, 1810-1820. https://doi.org/10.1109/TSG.2013.2274466

[50] Keeney, R.L. and Gregory, R.S. (2005) Selecting Attributes to Measure the Achievement of Objectives. Operations Research, 53, 1-11. https://doi.org/10.1287/opre.1040.0158 
Submit or recommend next manuscript to SCIRP and we will provide best service for you:

Accepting pre-submission inquiries through Email, Facebook, LinkedIn, Twitter, etc. A wide selection of journals (inclusive of 9 subjects, more than 200 journals)

Providing 24-hour high-quality service

User-friendly online submission system

Fair and swift peer-review system

Efficient typesetting and proofreading procedure

Display of the result of downloads and visits, as well as the number of cited articles Maximum dissemination of your research work

Submit your manuscript at: http://papersubmission.scirp.org/

Or contact sgre@scirp.org 